\title{
Liliana Silvia Landaburu In Memoriam (1955-2017)
}

\section{( Susana Presta}

Universidad de Buenos Aires, Instituto de Investigaciones Gino Germani / CONICET

\author{
Juan Carlos Radovich \\ Universidad de Buenos Aires, Instituto de Ciencias Antropológicas / CONICET
}

"La muerte no es verdad, cuando se ha cumplido bien la obra de la vida"

Escribir sobre una colega y amiga que partió a edad temprana resulta emotivamente condicionante, aunque imprescindible para dar a conocer la labor de una trabajadora excepcional en el campo de la antropología social.

Liliana fue una mujer valiente y determinada, tanto en su vida personal como académica. A pesar de las dificultades que puede acarrear comenzar una carrera universitaria alrededor de los cincuenta años, ella había trazado un horizonte hacia el cual avanzaría con tenacidad y excelencia.

Recordaremos siempre los largos debates que se planteaban ante nuevas preguntas de investigación. Su trabajo de campo se concentró, principalmente, en las estrategias y programas de desarrollo en el circuito productivo frutícola del Alto Valle de Río Negro, departamento de General Roca, en el norte de la Patagonia. El hecho de que ella misma y sus hijos tuviesen una vinculación directa con una de las empacadoras de frutas pertenecientes al campo de estudio constituyó un desafío, no solo metodológico, sino también emocional y político. No obstante, jamás dudó en construir un enfoque crítico respecto de ciertas prácticas naturalizadas que encerraban distintas formas de desigualdad para las unidades productivas del circuito. Liliana supo distanciarse, aunque no desde una posición "objetiva", sino a partir de una profunda claridad y reflexión respecto de su propia vivencia en relación con su problemática de investigación y su posición como antropóloga.

Los procesos socioeconómicos que analizó le permitieron observar que los programas de desarrollo y modernización del sector - los cuales se incluían dentro de otros más amplios vinculados al desarrollo territorial y local— estaban dirigidos a agentes con capacidad de acumulación; mientras que los pequeños y medianos productores debían adaptarse a estos cambios, a pesar de que sus unidades se encontraban en un 
proceso sistemático de descapitalización. Esto último le permitió pensar en unidades domésticas que funcionaban con la lógica del capital pero, paradójicamente, estaban descapitalizadas. En este contexto, construyó la noción de un "sector liminal", dentro del circuito que elaboraba una pluralidad de estrategias a fin de permanecer en él, dado que en la vida cotidiana de los chacareros convivían prácticas contradictorias que incidían en las formas de construcción de subjetividades.

Fue a partir de su trabajo de campo y su mirada crítica, que nuevas preguntas emergían en el proceso de investigación, a saber, aquellas en torno a las clásicas conceptualizaciones de la "unidad doméstica" — sus alcances y sus limitaciones-, sobre los procesos de subsunción del trabajo en el capital, la incidencia de organismos nacionales e internacionales y las formas en que se naturalizaban ciertas ideas y conceptos en relación con específicas formas de ejercicio del poder. Interrogantes que propiciaban largos debates en los cuales nunca olvidaremos su gran hospitalidad y los talentos culinarios de nuestra querida amiga, cuando la conversación se extendía demasiado pero las ideas rebullían sin descanso.

Su trabajo de tesis doctoral en antropología, Estrategias, productividad y subjetividad en el circuito productivo frutícola. Estudio de caso: última colonización planificada... (Landaburu, 2013), producto de las discusiones mencionadas, merece un comentario aparte. En efecto, luego de un prolongado trabajo de campo, pudo ver plasmada su eficiente investigación con el análisis de los datos recolectados. El objetivo fundamental fue analizar, desde la perspectiva de la antropología económica y rural, el proceso de trabajo en el circuito productivo frutícola en la región del Alto Valle del Río Negro, en función de la diferenciación laboral entre trabajadores rurales y trabajadores de empaques y frigoríficos, teniendo en cuenta también la movilización de la fuerza de trabajo, la constitución de subjetividades y las estrategias desplegadas por los diferentes actores sociales. Al respecto, Liliana consideraba el hecho económico "como un proceso social, donde lo político y la construcción de subjetividades legitiman prácticas y nuevas formas de dominación" (Landaburu, 2013: 252).

Asimismo, la complejidad de la temática no le impidió obtener excelentes resultados. Entre ellos, la reconstrucción histórica de los cambios técnicos y tecnológicos que operaron tanto en el circuito como en los modelos productivos y la gestión empresarial que justificaron estrategias organizacionales de los procesos de trabajo en su conjunto. Asimismo, logró describir las políticas productivas y su articulación con la demanda del mercado mundial, a partir del análisis en relación con la implementación de las políticas públicas. También logró analizar la articulación de las unidades domésticas con los complejos agroindustriales, las formas de trabajo, las prácticas de resistencia y/o adaptación a la demanda empresarial y, en este sentido, sus prácticas formales e informales. Ello fue complementado con el riguroso análisis de las subjetividades y sentidos que construyeron los sujetos a partir de su articulación y/o vinculación con dichos complejos, como así también las formas en que construyeron sus historias biográficas y sus proyecciones futuras, con el fin de dar cuenta de las representaciones que hacían los sujetos de sí mismos y de su mundo circundante, además de describir la vinculación de historia y habitus en relación con la vida cotidiana y el mundo del trabajo. Una vez conseguidos dichos objetivos, logró analizar en profundidad, y desde una perspectiva histórica y relacional, la dinámica del capital en el circuito productivo y los efectos que se generaron en su articulación con las unidades productivas y las relaciones laborales implicadas.

Asimismo, Liliana logró articular eficazmente las perspectivas complementarias aportadas por diversas disciplinas sociales, con el fin de ampliar su enfoque teórico/ metodológico. De este modo, con los aportes de la sociología y la historia económica, contextualizó los aspectos procesuales y temporales con aquellos estructurales y 
globales; mientras que, con el aporte de la etnografía, logró profundizar en la obtención de los datos microsociales y los existentes a nivel local. Todo ello redundó en el enriquecimiento del trabajo mediante la consideración que afirma que los datos cuantitativos y cualitativos no son términos opuestos o antagónicos sino complementarios, que permiten además poner en tensión las realidades subyacentes, siempre importantes a la hora de desnaturalizar las relaciones sociales.

Los excelentes resultados alcanzados en el trabajo de tesis tuvieron estrecha vinculación con el prolongado conocimiento vivencial que Liliana había adquirido sobre los productores del área estudiada. Ello redundó en relaciones cordiales que ayudaron a enriquecer su labor. Lo afirmado se ejemplifica con una frase que Liliana dedicara a los distintos pobladores en el acápite de agradecimientos en su trabajo doctoral: "Este trabajo, no podría haberse realizado sin la colaboración de los chacareros, encargados de galpones, trabajadores rurales, peones, familias que desinteresadamente me abrieron las puertas de sus vidas y se transformaron sin saberlo en los protagonistas anónimos de esta investigación" (Landaburu, 2013: 2).

En cuanto a su inserción institucional, Liliana participó como codirectora del proyecto "Economía Social y Solidaria en el ámbito rural-urbano. Políticas de Desarrollo y nuevas perspectivas de acumulación de capital" (Programa de Reconocimiento Institucional, Facultad de Filosofía y Letras, UBA. Período: 2008-2010) y, luego, como directora del proyecto "Economía Social y Solidaria en el ámbito rural. Políticas de desarrollo y nuevas perspectivas de acumulación de capital. Análisis de un emprendimiento turístico-cultural en Mechita, provincia de Buenos Aires" (Programa de Reconocimiento Institucional, Facultad de Filosofía y Letras, UBA. Período: 2010-2012). En ellos, compartió su espíritu crítico y sus conocimientos, siempre con el propósito de generar interrogantes. Demostró un gran compromiso con la construcción colectiva del conocimiento y el acompañamiento de los estudiantes en el proceso de investigación de manera generosa y comprensiva. Integró, también como investigadora, el Programa "Economía política y Formaciones Sociales de Fronteras: Etnicidades y territorios en redefinición", en la Sección Antropología Social del Instituto de Ciencias Antropológicas (SEANSO-ICA), de la misma Facultad. En dicho marco, efectuó aportes muy valiosos basados en su experiencia y conocimientos, y demostró además una gran calidad humana para el trabajo en equipo.

En los años de nuestra labor conjunta, compartimos investigaciones, procesos de ardua escritura y trabajos de investigación. Luego de nuestras lecturas, los debates se extendían y ensayábamos respuestas que pudieran darnos una pista para nuestros hallazgos en el campo. Liliana siempre fue una persona dispuesta a aprender y a cuestionar. Como buena antropóloga, se entusiasmaba con desnaturalizar ideas y nociones que invisibilizaban procesos complejos y entramados de relaciones de poder, lo cual le permitió construir un enfoque crítico en relación con procesos de desarrollo, formas de trabajo y procesos de construcción de subjetividades que, más tarde, plasmaría en sus tesis.

Con este espíritu de aprender y ampliar nuestros conocimientos, incursionábamos en distintas disciplinas como la filosofía y la teoría económica, siempre generando nuevas preguntas de investigación.

Uno de los frutos más satisfactorios de nuestro trabajo fue el dictado de seminarios de grado sobre distintos aspectos críticos de la economía social y solidaria y las políticas de desarrollo. La idea surgió de la necesidad de compartir resultados y discutir con los estudiantes nuestras hipótesis. Liliana fue una excelente profesora, comprometida, sagaz y abierta en sus planteos. 
La continuidad del seminario nos permitió organizar grupos de lectura y debate, integrados, en su mayoría, por estudiantes que habían cursado anteriormente con nuestro equipo. Liliana alimentó, en todo momento, el pensamiento crítico y la construcción colectiva de conocimiento. En este sentido, fue una persona muy querida por los estudiantes y se convirtió en una consejera solidaria.

Nuestra colega y amiga nunca será olvidada, porque fue y es una de esas personas entrañables y extrañables. Con paso firme, no solo supo superar obstáculos sino que, tras su partida, dejó para sus colegas, amigos y amigas, sus ideas, su alegría, su solidaridad, generosidad y valentía.

\section{Referencias Bibliográficas}

"Landaburu, L. S. (2013) Estrategias, productividad y subjetividad en el circuito productivo frutícola. Estudio de caso: última colonización planificada. Alto Valle de Río Negro. Departamento de General Roca". Tesis Doctoral en Antropología. Facultad de Filosofía y Letras. Universidad de Buenos Aires. 